\title{
Benefit-Cost Analysis of the Danish Sun Safety Campaign 2007-2015: Cost Savings from Sunburn and Sunbed Use Reduction and Derived Skin Cancer Reductions 2007-2040 in the Danish Population
}

\author{
Brian Køster $^{1}$ (D) . Maria K. H. Meyer ${ }^{1}$. Jes Søgaard ${ }^{2} \cdot$ Peter Dalum $^{1}$
}

Published online: 15 October 2019

(c) The Author(s) 2019, corrected publication 2019

\begin{abstract}
Background Ninety percent of skin cancers are avoidable. In Denmark, 16,500 cases of melanoma and keratinocyte cancers were registered in 2015. The Danish Sun Safety Campaign has campaigned since 2007, targeting overexposure to ultraviolet radiation. During 2007-2015, the key indicators of skin cancer, i.e. sunbed use and sunburn, showed annual reductions of $6 \%$ and $1 \%$, respectively.

Objectives We aimed to examine the financial savings to society as a result of the campaign reductions in skin cancer cases (2007-2040), and to examine the campaign's cost-benefit and return on investment (ROI).

Methods The analysis is based on existing data: (1) annual population-based surveys regarding the Danish population's behavior in the sun; (2) skin cancer projections; (3) relative risks of skin cancers from sunburn and sunbed use and (4) historical cancer incidences, combined with new data; (5) benefits from the avoided costs of skin cancer reductions; and (6) the costs of the Danish Sun Safety Campaign.

Results The results were based on a reduction of 9000 skin cancer cases, saving $€ 29$ million of which $€ 13$ million were derived from sunburn reductions and $€ 16$ million from reductions in sunbed use. The ROI was $€ 2.18$.

Conclusion Skin cancer prevention in Denmark is cost effective. Every Euro spent by the Danish Sun Safety Campaign saved the Danish health budget $€ 2.18$ in health expenses.
\end{abstract}

\section{Key Points for Decision Makers}

Skin cancer prevention was previously shown to be cost effective in Australia.

Skin cancer prevention is now shown to be cost effective in Denmark and has the potential to be cost effective in similar countries.

The skin cancer prevention return of investment is $>2.18$.

From a government perspective, skin cancer prevention is a good investment to decrease expenditure on skin cancer treatment, and as an available tool to implement against an increasing burden of disease in an aging population.

1 Department of Prevention and Information, Danish Cancer Society, Strandboulevarden 49, 2100 Copenhagen $\varnothing$, Denmark

2 Danish Centre for Health Economics, Department of Public Health, University of Southern Denmark, Odense, Denmark 


\section{Introduction}

Exposure to ultraviolet radiation (UVR) is the main risk factor for most skin cancers, including melanoma and keratinocyte cancers, squamous cell cancer (SCC), and basal cell cancer (BCC) [1, 2]. Intermittent exposure to UVR from both the sun and sunbeds, as well as sunburn history, are important factors in the etiology of melanoma [3, 4]. Melanoma and keratinocyte skin cancer incidence rates in Denmark are among the highest in the world, despite the distant location from the equator and a maximum ultraviolet index of 7 in the summer. The 5-year survival from skin cancer in Denmark is $>90 \%$ for melanoma (2011-2015), and even higher for keratinocyte cancers [5]. Nevertheless, mortality from melanoma and keratinocyte skin cancers comprised 285 and 65 deaths, respectively, in Denmark annually (2011-2015), and costs to society from treatment and productivity loss were estimated to be $€ 33$ million annually (2004-2008) [6]. A total of 2250 new cases of melanoma cancer and 14,250 new cases of keratinocyte cancer were registered in 2015, and 28,000 and 152,000 persons, respectively, had a previous melanoma or keratinocyte skin cancer diagnosis in a Danish population of 5,500,000 [5, 7]. It is estimated that in Denmark, more than $90 \%$ of skin cancers could be prevented $[8,9]$, meaning there is large potential for the prevention of excessive UV exposure in Denmark.

In 2007, the Danish Sun Safety Campaign was launched to reduce UV exposure, increase awareness, and to promote the use of sun protection strategies to be used in the peak period of UVR exposure. The main advice from the campaign was to seek shade, wear a sun hat and use protective clothing, use sunscreen, and do not use sunbeds. The campaign was a multi-component campaign that included the use of television advertising, social media, print media, press, public affairs, structural prevention, and volunteer efforts in several settings such as kindergartens, music festivals, and running events [10, 11].

Skin cancer projections from the campaign results showed large increases in the number of skin cancer cases, due to an aging population and expected skin cancer incidence trend. The results of the Sun Safety Campaign during 2007-2015 included annual reductions in the rates of sunbed use and sunburn of $6 \%$ and $1 \%$, respectively. The skin cancer projections (2007-2040) also showed reductions in the number of skin cancer cases of 16,000 and 14,000 as a result of reductions in sunbed use and sunburn, respectively, compared with no change in behavior $[12,13]$.

Skin cancer prevention campaigns in Australia were cost effective [14-16], however the Australian climate, ambient UV exposure, and exposure patterns are very different from Danish conditions. The benefits derived from skin cancer prevention in Denmark have not been previously estimated.
The aims of this study were to examine the financial savings to society as a result of the Danish Sun Safety Campaign, in total and stratified according to sunburn and sunbed reductions, respectively, as a consequence of a decreased number of skin cancer cases compared with the expected trend, and to examine the campaign's cost-benefit and return on investment (ROI).

\section{Methods}

\subsection{Overview}

This analysis was based on (1) annual population-based surveys regarding the Danish population's behavior in the sun [17-19]; (2) skin cancer projections from surveys [12, 13]; (3) the relative risks of skin cancers from sunburn and sunbed use risk behaviors [3, 20-22]; (4) development of historical cancer incidences from the NORDCAN database [5]; (5) benefits from the avoided costs of skin cancer reductions (MM, SCC and BCC) [6]; and (6) campaign costs, based on the funding budget of the Danish Sun Safety Campaign, as shown in Table 1.

The effects of the Danish Sun Safety Campaign during 2007-2015, in terms of the annual reduction in sunbed use and sunburn fraction, have been previously published [12, 13]. The evaluation was based on annual population-based surveys regarding the Danish population's behavior in the sun, of approximately 4000 persons annually and more than 30,000 in total.

Projections of future skin cancer incidence were estimated using the Prevent program [23, 24]. The projections were based on the effects of the campaign and were compared with the status quo using conservative and realistic estimates of the intervention scenarios to obtain an indication of the long-term impact of the campaign interventions on skin cancer incidence. The projections were published along with the campaign results $[12,13]$. In the conservative intervention scenario, the levels of risk behavior (sunbed use and sunburn) return to pre-campaign levels during 2016-2023, while in the realistic intervention scenario, the level of risk behavior is assumed irreversible and stays constant at the achieved 2015 level. The relative risk estimates used for the projections were 2.0, 1.3, and 1.6 for MM, SCC, and $\mathrm{BCC}$, respectively, for patients who had ever experienced sunburn, and 1.2/1.6 (>35 years/<35 years), 1.67, and 1.29 for MM, SCC, and BCC, respectively, for patients who had ever used a sunbed [20, 25].

The national incidence rates for melanoma and keratinocyte skin cancer (International Classification of Diseases, Tenth Revision [ICD-10] codes C43 and C44) by sex and 5 -year age groups were retrieved from the NORDCAN database [5]. The estimated annual percentage change (EAPC) 
Table 1 Applied risk estimates, cancer incidence rate change, behavior change rates and cost estimates

\begin{tabular}{|c|c|c|c|c|c|}
\hline & Applied data & & & & Source/description \\
\hline 1. Change in behavior [17-19] & $\begin{array}{l}\text { Relative risk per year for sun- } \\
\text { bed use, } 0.94\end{array}$ & $\begin{array}{l}\text { Relative risk per year for } \\
\text { sunburn, } 0.99\end{array}$ & & & $\begin{array}{l}\text { Annual population-based surveys } \\
\text { regarding the Danish popula- } \\
\text { tion's sun behavior }\end{array}$ \\
\hline \multirow[t]{4}{*}{$\begin{array}{l}\text { 2. Projected change in cancer } \\
\text { incidence }[12,13]\end{array}$} & \multicolumn{4}{|l|}{ EAPC15 (main) } & $\begin{array}{l}\text { EAPC and constant for the } \\
\text { remaining years } \\
4 \% \text { used for MM, SCC, and BCC } \\
\text { in } 15 \text { years, and afterwards set } \\
\text { to } 0 \%\end{array}$ \\
\hline & \multicolumn{4}{|l|}{ EAPC0 (sensitivity) } & $\begin{array}{l}4 \% \text { used for } \mathrm{MM}, \mathrm{SCC} \text {, and } \mathrm{BCC} \\
\text { in } 0 \text { years, and afterwards set } \\
\text { to } 0 \%\end{array}$ \\
\hline & \multicolumn{4}{|l|}{ EAPC30 (sensitivity) } & $\begin{array}{l}4 \% \text { used for } \mathrm{MM}, \mathrm{SCC} \text {, and } \mathrm{BCC} \\
\text { in } 30 \text { years, and afterwards set } \\
\text { to } 0 \%\end{array}$ \\
\hline & & MM & SCC & $\mathrm{BCC}$ & \\
\hline $\begin{array}{l}\text { 2a. Avoided cancer cases [12, } \\
\text { 13] }\end{array}$ & $\begin{array}{l}\text { Also summarized in Figs. 1, 3, } \\
\text { S1a, S2a }\end{array}$ & 2485 & 3623 & 8176 & \\
\hline \multirow[t]{2}{*}{ 3. Risk estimates $[3,20-22]$} & Sunburn & 2.0 & 1.3 & 1.6 & \\
\hline & Sunbed use & $\begin{array}{l}1.2 / 1.6 \\
(>35 \text { years } /<35 \text { years })\end{array}$ & 1.67 & 1.29 & \\
\hline 4. Cancer incidence [5] & $\begin{array}{l}\text { Available from the NORDCAN } \\
\text { database }\end{array}$ & & & & $\begin{array}{l}\text { 5-year age-specific intervals for } \\
\text { males and females were used }\end{array}$ \\
\hline \multirow[t]{2}{*}{ 5. Cost estimates [6] } & Applied (2006 value) & $€ 10,263$ & $€ 6435$ & $€ 1859$ & \\
\hline & 2019 value & $€ 13,108$ & $€ 8219$ & $€ 2374$ & $3 \%$ annual inflated rates \\
\hline 6. Campaign budget & $€ 13.5$ millon & & & & $\begin{array}{l}\text { Costs were calculated from } \\
\text { expenses from the Danish } \\
\text { Cancer Society and funding } \\
\text { from Trygfonden. Data were } \\
\text { retrieved from the Danish } \\
\text { Cancer Society, Department of } \\
\text { Prevention accounting }\end{array}$ \\
\hline
\end{tabular}

$M M$ malignant melanoma, $S C C$ squamous cell carcinoma, $B C C$ basal cell carcinoma, $E A P C$ estimated average percentage change for $x$ years

for men and women for the past 25 years was $6.4 \%$ and $10.9 \%$ increase for SCC, $5.4 \%$ and $7.4 \%$ for BCC and $4.4 \%$ and $4.5 \%$ for melanoma, respectively [5]. However, for the modeling, a uniform conservative $4 \%$ increase was applied for all skin cancer rates for men and women. The EAPC was applied for the first 15 years, after which it remained constant at this level.

The effect of a risk factor exposure on cancer incidence has a latency time. We accommodated this through two time lags: (1) the time that the risk remains unchanged after a decline in risk factor exposure (LAT); and (2) the period during which the changes in risk factor exposure gradually affect the risk of cancer, eventually reaching risk levels of the non-exposed (LAG) [23]. LAG was modeled as a linearly declining risk.

For sensitivity analysis, we applied the EAPC of 0 and 30 years, and the half and double latency periods $(\mathrm{LAT}+\mathrm{LAG})$.

Benefit estimation was based on avoided health costs from melanoma and keratinocyte skin cancers. These were estimated by determining the annual healthcare costs and productivity losses per patient compared with similar costs in a matched control cohort. Productivity losses, from a society perspective, included losses related to reduced labor supply. Productivity losses for the patient's caregivers or other informal care are not available for register-based studies and were therefore not included. Social transfer payments were measured, and comprised income derived from public offers: subsistence allowances, social security, social assistance, pensions, public personal support for education, and other payments. Productivity costs and social transfers were based on data from the Danish Coherent Social Statistics Register. Healthcare costs included hospitalization, outpatient visits, medication, and other consultations with general practitioners and dermatologists, for example; non-financial benefits were excluded [6].

The benefit-cost analysis uses 2006-2007 as the reference years, and adopted a societal perspective. In a benefit-cost analysis, a ratio can be created by dividing benefits over costs, referred to as a benefit-cost ratio. A ratio $>1$ 
demonstrates a positive ROI. In this analysis, the potential benefits are measured as treatment and productivity costs avoided due to reducing the incidence of skin cancer. Other health benefits, e.g. quality-adjusted life-years, were not quantified. Mortality was also not included in the analysis. The costs also included the costs of the Danish Sun Safety Campaign. All future costs are converted to present-day values using a $3 \%$ discount rate.

As the analysis is based on an achieved change in behavior, an unknown development in behavior from 2015 onwards, and an estimated development in skin cancer incidence, our analysis included sensitivity analysis based on sensitivity scenarios previously described in detail $[12,13]$.

\section{Results}

Figure 1 displays expected avoided skin cancer cases (MM, SCC, BCC, and total) [2007-40] as a result of reductions in patients who experienced sunburn [13], reductions in sunbed use [12], and combined reductions from both sunburn and sunbed use during 2007-2015. The largest reductions in the number of skin cancer cases are as a result of reductions in sunbed use. In total, the campaign is estimated to have avoided nearly 9000 cases of skin cancer in the conservative scenario. Figure 2 shows the estimated avoided health costs associated with reductions in skin cancer. Skin cancer reductions due to reductions in sunburn have cost savings of almost $€ 13$ million, sunbed use $€ 16$ million, and combined $€ 29$ million. The largest savings are for MM, at almost $€ 20$ million. In electronic supplementary Fig. S1, we show the reductions in skin cancer in a scenario where the campaign effect is irreversible (constant), which results in skin cancer reductions of about 30,000 cases. Correspondingly, electronic supplementary Fig. S2 shows that the cost saving for this scenario was $€ 90$ million.

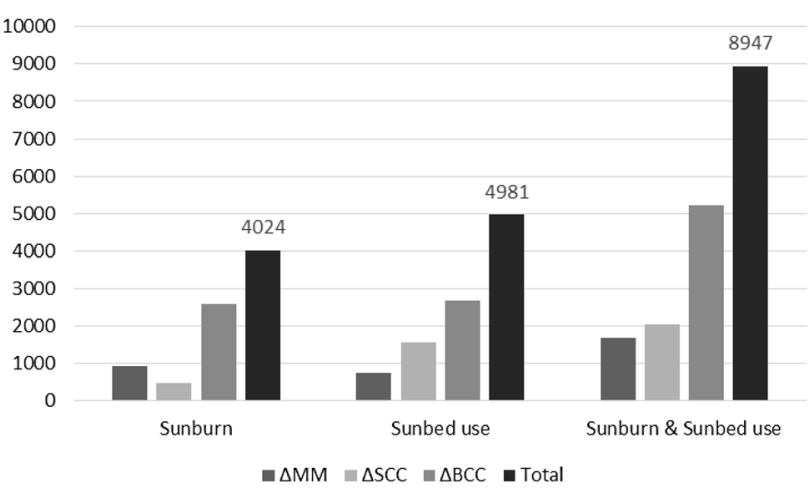

Fig. 1 Expected avoided skin cancers (2007-2040) as a result of a reduction in the prevalence of sunburn and sunbed use (2007-2015), distributed according to skin cancer type. $M M$ malignant melanoma, $S C C$ squamous cell carcinoma, $B C C$ basal cell carcinoma

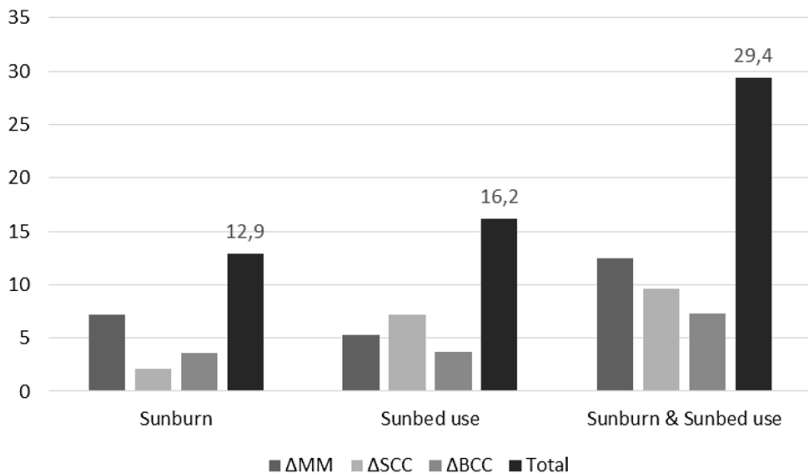

Fig. 2 Expected cost savings ( $€$, millions) from skin cancer reductions (2007-2040), distributed according to UV exposure reduction and skin cancer type. $M M$ malignant melanoma, $S C C$ squamous cell carcinoma, $B C C$ basal cell carcinoma, $U V$ ultraviolet

Figure 3 compares our base case with our sensitivity scenarios regarding skin cancer reductions. If we assume that the EAPC of MM, SCC, or BCC is increasing at $4 \%$ annually for zero years (i.e. not increasing) instead of increasing over 15 years, the campaign would have saved only 5380 skin cancer cases instead of 8947 due to a development with a smaller total number of cases. Conversely, if the latency time was twice as long, the campaign would have saved 10,424 cases. These numbers represent the minimum and maximum estimates of our analysis of the conservative scenario. Correspondingly, Fig. 4 shows that the minimum and maximum estimates of saved costs were $€ 17$ million and $€ 32$ million, respectively. The cost savings were largest when the analysis applied the EAPC for 30 years.

The costs of the Danish Sun Safety Campaign during 2007-2015 were Danish krone (DKK) 100 million, i.e. approximately $€ 13.5$ million. This amount was distributed evenly over the campaign period, but with slightly higher

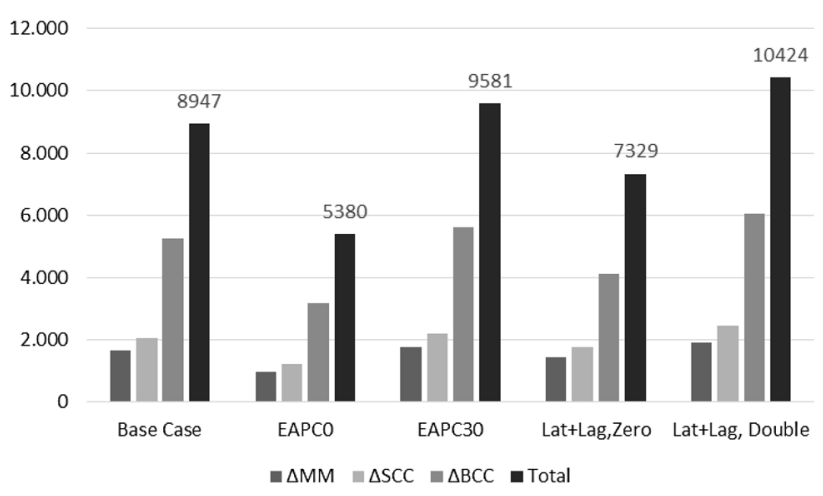

Fig. 3 Expected avoided skin cancers (2007-2040) in sensitivity variations of cancer trend and latency time (lat +lag), distributed according to skin cancer type. $M M$ malignant melanoma, $S C C$ squamous cell carcinoma, $B C C$ basal cell carcinoma, EAPC estimated average percentage change for $x$ years 


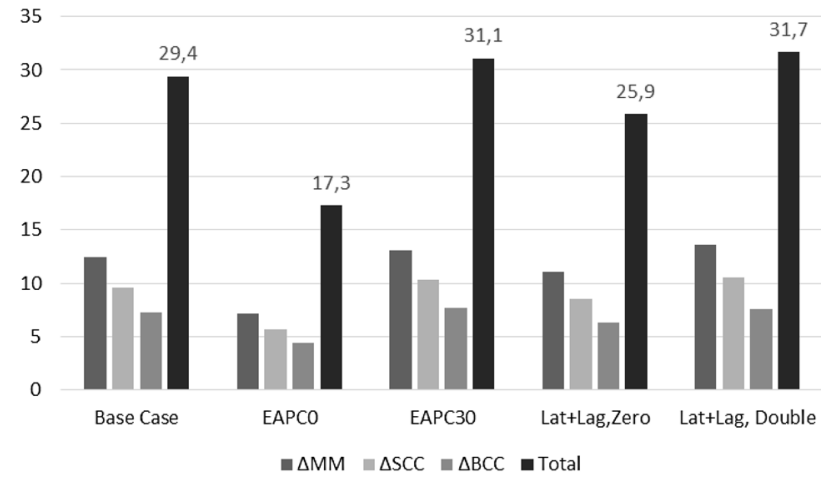

Fig. 4 Expected cost savings ( $€$, millions) from skin cancer reductions (2007-2040) in sensitivity variations of cancer trend and latency time (lat + lag), distributed according to skin cancer type. $M M$ malignant melanoma, SCC squamous cell carcinoma, $B C C$ basal cell carcinoma, EAPC estimated average percentage change for $x$ years

funding in 2010-2013 compared with 2007-2009 and 2014-2015.

In our conservative scenario, where the effect of the campaign was reversed, we reported a benefit-cost ratio of 2.18 and minimum and maximum ratios from our sensitivity analysis of 1.26 and 2.37 , respectively. In our realistic scenario, where the campaign effect was not reversed but was constant, a benefit-cost ratio of 6.68 was reported.

\section{Discussion}

We have shown that during 2007-2015, the Danish Sun Safety Campaign was cost effective in a very conservative estimation, where all effects have returned to pre-campaign levels of sunburn and sunbed use. We have also shown that there is great value in actually achieving a realistic scenario, i.e. where levels of sunburn and sunbed use do not return to pre-campaign levels, with potential cost savings of $€ 90$ million during 2007-2040.

\subsection{Strength and Limitations}

We used cost estimates from the work of Bentzen et al. [6] as the estimates were similar for all skin cancer types. Newer data from the work of Kruse et al. [26] did not include BCC. The cost estimates for MM and SCC were $4 \%$ and $41 \%$ higher, respectively, in the work of Kruse et al. compared with the work of Bentzen et al. $[6,26]$. Guy et al. showed a large increase in the costs of skin cancer treatment in the US [27], and while new treatments have been introduced in Denmark, any potential cost increase from drugs with a melanoma indication (ipilimumab, vemurafenib, dabrafenib and trametinib) occurred after the establishment of our applied cost estimates and were therefore not included in our analysis [28]. Overall, this suggests we could underestimate the costs in the analysis, which would increase the benefit-cost ratio.

Recently validated sun behavior surveys were applied for the evaluation of population UVR exposure in Denmark [29-31]. Previous questionnaires, as applied in our study, may be more prone to social desirability bias, which could decrease the measured effect of the skin cancer prevention campaigns; however, experiences from Australia do not imply this to be the case [32].

Our results are based on skin cancer projections. If the incidence projections are higher or lower than actual development, the Danish Sun Safety Campaign may be less or more cost effective than shown. However, we provided sensitivity analysis of the calculations, and either of the calculations was shown to be cost effective (benefit-cost ratio $>1$ ).

Differential increases in cancer stage were not included in the analysis. The tumor size, node and metastasis (TNM) classification stage of diagnosis was shown to influence treatment cost drastically, and changes in TMN stage distribution may influence our results [33]; however, while thin melanomas $(<1 \mathrm{~mm})$ were shown to have increased more than thicker melanomas ( $>1 \mathrm{~mm}$ ) during 1985-2012, an increase in melanoma was shown for all thicknesses [34]. Likewise, the incidence rate for melanoma in Denmark is no longer increasing and seems to have reached a plateau, indicating that an increasingly steeper increase in thin melanomas compared with thicker melanomas is not likely [35].

\subsection{Interpretation}

As the Danish campaign continues in 2019, and will exist at least until 2022, there are no indications that the levels of sunbed use and sunburn will reverse. The exact benefit-cost ratio can be influenced by many factors. We have included some in our sensitivity analysis, but there may be others we were not able to account for due to the nature of a projection study, e.g. the potential effects of telemedicine on treatment costs or medicine prices.

\subsection{Cost-Benefit of Skin Cancer Prevention}

In Australia, several studies have shown the cost-benefit of skin cancer prevention [15, 16, 36], with ROI estimates of more than \$3 gained for each dollar invested. Other studies have modeled benefits, costs, or scenarios of skin cancer prevention; however, to the best of our knowledge, Denmark is the first European country to report the financial benefits of actual campaign results achieved [14, 37, 38].

The broader the health costs are defined, the larger the avoided costs are, and hence the benefit-cost ratio. A 
Swedish health costs study included mortality and loss of production [39] and reported much higher health costs than the Danish estimates. In addition, we have only assessed financial benefits, not other welfare benefits associated with the reduced risks of skin cancer. In Australia, skin cancer prevention has now been ongoing for more than 30 years, which provides the possibility of tracking other more direct measures. It was also shown that the incidence of skin cancer has curbed [40-42], which indicates that this would also be possible in Denmark and other countries investing in skin cancer prevention.

\section{Conclusions}

The financial benefits from investment in skin cancer prevention were much higher than the campaign costs in Denmark. Skin cancer is the most common cancer in the world and the vast majority of skin cancers are avoidable by sensible behavior in the sun and by avoiding sunbed use. Many resources are spent on treating skin cancer. Investing in skin cancer prevention would eventually reduce the total expenditure on skin cancer. In our study, we showed, in a conservative scenario, that every Euro spent by the campaign saved the Danish health budget $€ 2.18$ in health expenses.

Author Contributions All authors contributed to the conception, design, analysis, and interpretation of this study. BK drafted the work, and all authors revised it critically for important intellectual content, approved the version to be published, and agreed to be accountable for all aspects of this work in ensuring that questions related to the accuracy or integrity of any part of the work are appropriately investigated and resolved.

Data Availability Statement The datasets generated and/or analyzed during the current study are available from the corresponding author upon reasonable request.

\section{Compliance with Ethical Standards}

Funding This study was supported by TrygFonden.

Conflict of interest Brian Køster, Maria K.H. Meyer, Jes Søgaard, and Peter Dalum have no competing interests to declare. The funders had no role in the study design, data collection and analysis, decision to publish, or preparation of the manuscript.

Open Access This article is distributed under the terms of the Creative Commons Attribution-NonCommercial 4.0 International License (http://creativecommons.org/licenses/by-nc/4.0/), which permits any noncommercial use, distribution, and reproduction in any medium, provided you give appropriate credit to the original author(s) and the source, provide a link to the Creative Commons license, and indicate if changes were made.

\section{References}

1. Armstrong BK, Kricker A. The epidemiology of UV induced skin cancer. J Photochem Photobiol, B. 2001;63(1-3):8-18.

2. International Agency for Research on Cancer. Monograph 100 D-solar and ultraviolet radiation. Lyon: International Agency for Research on Cancer; 2011. p. 35-102.

3. Gandini S, et al. Meta-analysis of risk factors for cutaneous melanoma: II. Sun exposure. Eur J Cancer. 2005;41(1):45-60.

4. Veierod MB, et al. Sun and solarium exposure and melanoma risk: effects of age, pigmentary characteristics, and nevi. Cancer Epidemiol Biomark Prev. 2010;19(1):111-20.

5. Engholm G, et al. NORDCAN: cancer incidence, mortality, prevalence and survival in the Nordic countries, Version 7.3 (08.07.2016). Association of the Nordic Cancer Registries. Danish Cancer Society. 2016. http://www.ancr.nu. Accessed 15 Aug 2016.

6. Bentzen J, et al. Costs of illness for melanoma and nonmelanoma skin cancer in Denmark. Eur J Cancer Prev. 2013;22(6):569-76.

7. The Danish Board of Health. New cancer cases in Denmark 2016 [in Danish]. The Danish Cancer Registry; 2017.

8. Lucas RM, et al. Estimating the global disease burden due to ultraviolet radiation exposure. Int J Epidemiol. 2008;37(3):654-67.

9. Arnold M, et al. Global burden of cutaneous melanoma attributable to ultraviolet radiation in 2012. Int J Cancer. 2018;143(6):1305-14.

10. Koster B, et al. Prevalence of sunburn and sun-related behaviour in the Danish population: a cross-sectional study. Scand J Public Health. 2010;38(5):548-52.

11. Koster B, et al. Sunbed use in the Danish population in 2007: a cross-sectional study. Prev Med. 2009;48(3):288-90.

12. Køster B, et al. Sunbed use 2007-2015 and skin cancer projections of campaign results 2007-2040 in the Danish population: repeated cross-sectional surveys. BMJ Open. 2018;8(8):e022094.

13. Køster B, Meyer M, Andersson T, Engholm G, Dalum P. Development in sunburn 2007-2015 and skin cancer projections 20072040 of campaign results in the danish population. Medicine (Baltimore). 2018;97(41):e12738.

14. Gordon LG, Rowell D. Health system costs of skin cancer and cost-effectiveness of skin cancer prevention and screening: a systematic review. Eur J Cancer Prev. 2015;24(2):141-9.

15. Shih ST, et al. Economic evaluation of skin cancer prevention in Australia. Prev Med. 2009;49(5):449-53.

16. Doran CM, et al. Benefit cost analysis of three skin cancer public education mass-media campaigns implemented in New South Wales, Australia. PLoS ONE. 2016;11(1):e0147665.

17. Mortensen JH, Behrens CL, Køster B. Danskernes solvaner i sommerferien 2015-en ugebaseret dataindsamling. København: Kræftens Bekæmpelse og TrygFonden smba (TryghedsGruppen smba); 2017.

18. Krarup AF, et al. Sun exposure habits of the Danes in the Danish summer 2010 [in Danish]. Solundersøgelsen 2010_En kortlægning af danskernes solvaner i den danske sommer. 2011. pp. 1-59. http://www.skrunedforsolen.dk. Accessed 1 Jun 2018.

19. Koster B, et al. Sunbed use and campaign initiatives in the Danish population, 2007-2009: a cross-sectional study. J Eur Acad Dermatol Venereol. 2011;25(11):1351-5.

20. Boniol M, et al. Cutaneous melanoma attributable to sunbed use: systematic review and meta-analysis. BMJ. 2012;345:e4757.

21. Wehner MR, et al. International prevalence of indoor tanning: a systematic review and meta-analysis. JAMA Dermatol. 2014;150(4):390-400. 
22. International Agency for Research on Cancer. Radiation: volume $100 \mathrm{D}$ - a review of human carcinogens. International Agency for Research on Cancer (IARC), World Health Organization (WHO); 2012.

23. Soerjomataram I, et al. Impact of a smoking and alcohol intervention programme on lung and breast cancer incidence in Denmark: an example of dynamic modelling with Prevent. Eur J Cancer. 2010;46(14):2617-24.

24. Barendregt J. Software information. http://epigear.com. Cited 1 Oct 2016.

25. Wehner MR, et al. Indoor tanning and non-melanoma skin cancer: systematic review and meta-analysis. BMJ. 2012;345:e5909.

26. Kruse M, Hostenkamp G. Societal economic cost of cancer [in Danish]. Danish Centre for Health Economics, University of Southern Denamrk, 2016.

27. Guy GP Jr, et al. Prevalence and costs of skin cancer treatment in the U.S., 2002-2006 and 2007-2011. Am J Prev Med. 2015;48(2):183-7.

28. New cancer cases in Denmark 2016. The cancer registry [In Danish]. Copenhagen

29. Koster B, et al. Effects of smartphone diaries and personal dosimeters on behavior in a randomized study of methods to document sunlight exposure. Prev Med Rep. 2016;3:367-72.

30. Koster B, et al. The validated sun exposure questionnaire: association of objective and subjective measures of sun exposure in a Danish population based sample. Br J Dermatol. 2017;176(2):446-56.

31. Koster B, et al. Feasibility of smartphone diaries and personal dosimeters to quantitatively study exposure to ultraviolet radiation in a small national sample. Photodermatol Photoimmunol Photomed. 2015;31(5):252-60.

32. Dobbinson SJ, Wakefield MA, Jamsen KM, Herd NL, Spittal MJ, Lipscomb JE, et al. Weekend sun protection and sunburn in Australia trends (1987-2002) and association with sunsmart television advertising. Am J Prev Med. 2008;34(2):94-101.

33. Elliott TM, et al. Estimated healthcare costs of melanoma in Australia over 3 years post-diagnosis. Appl Health Econ Health Policy. 2017;15(6):805-16.

34. Helvind NM, et al. Incidence of in situ and invasive melanoma in Denmark from 1985 through 2012: a national database study of 24,059 melanoma cases. JAMA Dermatol. 2015;151(10):1087-95.

35. Engholm G, et al. NORDCAN: Cancer incidence, mortality, prevalence and survival in the Nordic countries, version 8.0 (20.12.2017). Association of the Nordic Cancer Registries. Danish Cancer Society. 2017. http://www.ancr.nu. Accessed 1 Mar 2018.

36. Shih ST, et al. Economic evaluation of future skin cancer prevention in Australia. Prev Med. 2017;99:7-12.

37. Gordon LG, et al. Modelling the healthcare costs of skin cancer in South Africa. BMC Health Serv Res. 2016;16:113.

38. Pil L, et al. Burden of skin cancer in Belgium and cost-effectiveness of primary prevention by reducing ultraviolet exposure. Prev Med. 2016;93:177-82.

39. Nilsson GH, et al. Skin diseases caused by ultraviolet radiation: the cost of illness. Int $\mathbf{J}$ Technol Assess Health Care. 2003;19(4):724-30.

40. Aitken JF, et al. Generational shift in melanoma incidence and mortality in Queensland, Australia, 1995-2014. Int J Cancer. 2018;142(8):1528-35.

41. Wallingford SC, et al. Comparison of melanoma incidence and trends among youth under 25 years in Australia and England, 1990-2010. Int J Cancer. 2015;137(9):2227-33.

42. Iannacone MR, et al. Melanoma incidence trends and survival in adolescents and young adults in Queensland, Australia. Int J Cancer. 2015;136(3):603-9. 